\title{
Studies on the effectiveness of SCR catalysts during combustion of pulverized coal
}

\author{
Marek Pronobis ${ }^{*}$, Sylwester Kalisz ${ }^{1}$, Kazimierz Mroczek $^{1}$, Andrzej Walewski ${ }^{1}$, Robert \\ Wejkowski ${ }^{1}$, Wactaw Wojnar ${ }^{1}$, Waldemar Gądek ${ }^{1}$, Tomasz Kress ${ }^{1}$, Mateusz Tymoszuk ${ }^{1}$, \\ Izabella $\mathrm{Maj}^{1}$
}

${ }^{1}$ Silesian University of Technology, Institute of Power Engineering and Turbomachinery, Division of Boilers and Steam Generators, Konarskiego 20, 44-100 Gliwice, Poland

\begin{abstract}
The motivation of this paper is new NOx emission regulations according to IED Directive 2010/75/EU of EU which introduce the BAT's conclusions as binding. The paper presents the methodology and results of research on the effectiveness of SCR catalysts during combustion of pulverised coal in a model furnace installed at the Institute of Power Engineering and Turbomachinery of the Silesian University of Technology (IPET). The aim of the research was to search for catalysts that could be placed in a regenerative rotary air heater - RAH-SCR. Two catalysts were tested: a commercial plate-type based on $\mathrm{V}_{2} \mathrm{O}_{5}$ and a prototype ceramic based on platinum. Presented results of investigation demonstrate a potentially high efficiency of RAH-SCR installations which can meet new environmental regulations of NOx emission. The highest NOx reduction efficiency $(92.87 \%)$ was obtained for an industrial catalyst at $329^{\circ} \mathrm{C}$, from about 436.3 to $31.1 \mathrm{mg} / \mathrm{m}^{3}$ as $\mathrm{NO}_{2} @ 6 \% \mathrm{O}_{2}$ to 31,1 . At lower temperature, $260^{\circ} \mathrm{C}$ maximum efficiency of NOx reduction does not exceed $60 \%$, from 440,0 to $169,6 \mathrm{mg} / \mathrm{m}^{3}$. The placement of the catalyst in the RAH can also be a support for SNCR installations due to the increase in DeNOx efficiency and reduction of $\mathrm{NH}_{3}$ slip.
\end{abstract}

\section{Introduction}

New law regulations according to IED Directive [1] establish BAT (Best Available Techniques) for large combustion plants (thermal input 50MW or more). The respective decision [2] has been published 31 July 2017, and these requirements will become effective in mid-2021. In terms of NOx emissions, this corresponds to the following levels (Table 1).

\footnotetext{
*Corresponding author: marek.pronobis@polsl.pl,
} 
Table 1. $\mathrm{NO}_{2}$ emission standards of BAT conclusions

\begin{tabular}{|c|c|c|c|c|}
\hline \multirow{2}{*}{ Parameter } & \multirow{2}{*}{ Unit } & \multirow{2}{*}{ Current limit } & \multicolumn{2}{|c|}{ BAT conclusions } \\
\cline { 4 - 5 } & & & Existing plants & New plants \\
\hline $\mathrm{NO}_{2}$ limit & $\mathrm{mg} / \mathrm{mu}^{3} @ 6 \% \mathrm{O}_{2}$ & 200 & $\begin{array}{c}65-150^{*} \\
<85-200^{* *}\end{array}$ & $\begin{array}{c}65-85^{*} \\
80-125^{* *}\end{array}$ \\
\hline
\end{tabular}

* annual average; ** daily average

The SCR technology is practically one which can meet the new regulations. The development of SCR technology is essential for the power industry. In the case of SCR, there are many references describing the current state of the art $[3,4,5]$.

The reagent is injected into the flue gas duct in front of the catalyst. The result is the conversion of nitrogen oxides $\mathrm{NOx}$ to the surface of the catalyst, most often at a temperature between $300^{\circ} \mathrm{C}-400^{\circ} \mathrm{C}$ in the presence of oxygen contained in the flue gas:

- if the reducing agent is ammonia, then:

or

$$
4 \mathrm{NO}+4 \mathrm{NH}_{3}+\mathrm{O}_{2} \leftrightarrow 4 \mathrm{~N}_{2}+6 \mathrm{H}_{2} \mathrm{O}
$$

$$
6 \mathrm{NO}_{2}+8 \mathrm{NH}_{3} \leftrightarrow 7 \mathrm{~N}_{2}+12 \mathrm{H}_{2} \mathrm{O}
$$

- $\quad$ if the reducing agent is urea, thus

$$
4 \mathrm{NO}+2\left(\mathrm{NH}_{2}\right)_{2} \mathrm{CO}+2 \mathrm{H}_{2} \mathrm{O}+\mathrm{O}_{2} \leftrightarrow 4 \mathrm{~N}_{2}+6 \mathrm{H}_{2} \mathrm{O}+2 \mathrm{CO}_{2}
$$

or

$$
6 \mathrm{NO}_{2}+4\left(\mathrm{NH}_{2}\right)_{2} \mathrm{CO}+4 \mathrm{H}_{2} \mathrm{O} \leftrightarrow 7 \mathrm{~N}_{2}+12 \mathrm{H}_{2} \mathrm{O}+4 \mathrm{CO}_{2}
$$

Because of health and safety rules for transport and storage, the most used is aqueous ammonia. An important argument against the introduction of urea solution into the convection part of the boiler is its corrosiveness. Condensed ammonia (liquid form) must be converted into a gaseous form. In industrial application solution of aqueous ammonia is evaporated on temperature $180-250{ }^{\circ} \mathrm{C}$ and is mixed with compressed air; after that gaseous mixture is injected into spraying nozzles. The appropriate mixing of the reactant with flue gas is also necessary to obtain efficient $\mathrm{NO}_{\mathrm{x}}$ reduction $[6,7]$.

To minimize the $\mathrm{NH}_{3}$ slip, the optimal ratio $\mathrm{NH}_{3} / \mathrm{NOx}$ must be maintained $[3,8,9]$. Maximal dose of $\mathrm{NH}_{3}$ and achieved $\mathrm{NOx}$ reduction is determined by catalyst characteristic, its geometry and shape, porosity and thus active catalyst surface and gas residence time [5]. However many factors could decrease reduction effect such as: fouling and formation of ABS (ammonium bisulphate), ammonia chlorides and other species, adsorption and absorption of $\mathrm{NH}_{3}$ on fly ash, catalyst corrosion and erosion and blockage of catalyst active centres and its deactivation by heavy metals mainly arsenic and alkali metals ( $\mathrm{Na}, \mathrm{K})$.

\section{Methodology}

In this study SCR experiments were carried out on Drop Tube Reactor (DTR) equipped and adapted for SCR tests. A significant advantage of this installation is high flexibility and the simplicity of controlling the process parameters that imitate the work of SCR an industrial installation. In Fig. 1. experimental facility is presented. The reactor is electrically heated heat-resistant and acid-resistant stainless steel tube with an inner diameter $300 \mathrm{~mm}$. Reactor is equipped with pulverised fuel burner, fuel and air supply system, data acquisition and control system. The catalyst is placed in a specially prepared SCR section. SCR section is 
equipped with a 3 stage static mixer providing proper mixing ammonia with the flue gas, before the catalyst. Ammonia dosing system is fitted with high-quality spraying nozzle. To increase the flue gas and reagent mixing efficiency, the mix of ammonia with neutral gas $\mathrm{N}_{2}$ is applied. The lab SCR installation has a wide control range of Area Velocity (depend on the type of catalysts) and of $\mathrm{NH}_{3} / \mathrm{NO}$ ratio 0-6.

Investigated fuel was the hard coal from the Polish mine KWK Sobieski. Fuel represents typical coal utilized in the Polish power sector. It is characterized by high Lower Heating Value $\mathrm{Q}^{\mathrm{d}}{ }_{\mathrm{i}}=27.24 \mathrm{MJ} / \mathrm{kg}$ and high volatiles content $\mathrm{V}^{\mathrm{daf}}=41.76 \%$ enabling easy ignition. Ultimate, proximate, ash oxides and ash fusibility analyses, and heavy metals content were investigated in a certified laboratory. The results of the analysis are presented in Table 2. For proper burnout in DTR hard coal were milled to cumulative percentage retained $\mathrm{R}_{0.2} \leq$ $1 \%$.

Table 2. Basic analysis of coal

\begin{tabular}{|c|c|c|c|c|c|c|c|}
\hline \multirow{4}{*}{$\begin{array}{l}\text { Ash oxides } \\
\text { analysis }\end{array}$} & $\mathrm{SiO}_{2}(\%)$ & $\mathrm{CaO}(\%)$ & $\mathrm{K}_{2} \mathrm{O}(\%)$ & $\mathrm{P}_{2} \mathrm{O}_{5}(\%)$ & $\mathrm{Al}_{2} \mathrm{O}_{3}(\%)$ & $\mathrm{MgO}(\%)$ & $\mathrm{Fe}_{2} \mathrm{O}_{3}(\%)$ \\
\hline & 53.4 & 2.52 & 2.51 & 0.16 & 24.3 & 1.53 & 8.48 \\
\hline & $\mathrm{SO}_{3}(\%)$ & $\mathrm{Na}_{2} \mathrm{O}(\%)$ & $\mathrm{TiO}_{2}(\%)$ & $\mathrm{Cl}(\%)$ & $\mathrm{BaO}(\%)$ & $\mathrm{SrO}(\%)$ & $\mathrm{Mn}_{3} \mathrm{O}_{4}(\%)$ \\
\hline & 2.36 & 2.70 & 0.89 & - & 0.08 & 0.04 & 0.04 \\
\hline \multirow{2}{*}{$\begin{array}{c}\text { Ultimate } \\
\text { analysis of } \\
\text { fuel }\end{array}$} & $\mathrm{C}^{\mathrm{d}}(\%)$ & $\mathrm{H}^{\mathrm{d}}(\%)$ & $\mathrm{S}^{\mathrm{d}}(\%)$ & $\mathrm{N}^{\mathrm{d}}(\%)$ & $\mathrm{Cl}^{\mathrm{d}}(\%)$ & $\mathrm{O}^{\mathrm{d}}(\%)$ & $\mathrm{Q}^{\mathrm{d}_{\mathrm{i}}}(\mathrm{MJ} / \mathrm{kg})$ \\
\hline & 74.71 & 3.15 & 0.86 & 1.07 & 0.146 & 10.36 & 27.24 \\
\hline \multirow{2}{*}{$\begin{array}{c}\begin{array}{c}\text { Proximate } \\
\text { analysis of } \\
\text { fuel }\end{array} \\
\end{array}$} & $\mathrm{W}^{\mathrm{r}}(\%)$ & $\mathrm{A}^{\mathrm{d}}(\%)$ & $V^{\text {daf }}(\%)$ & & & & \\
\hline & 2.6 & 9.7 & 41.76 & & & & \\
\hline \multirow{2}{*}{$\begin{array}{c}\text { Ash } \\
\text { fusibility } \\
\text { temperature } \\
\text { red./oxy. }\end{array}$} & IDT $\left({ }^{\circ} \mathrm{C}\right)$ & $\mathrm{ST}\left({ }^{\circ} \mathrm{C}\right)$ & $\mathrm{HT}\left({ }^{\circ} \mathrm{C}\right)$ & FT $\left({ }^{\circ} \mathrm{C}\right)$ & & & \\
\hline & $1150 / 1250$ & $1210 / 1280$ & $1240 / 1350$ & $1310 / 1400$ & & & \\
\hline \multirow{2}{*}{$\begin{array}{c}\text { Heavy } \\
\text { metals } \\
\text { content in } \\
\text { fuel }\end{array}$} & $\mathrm{Hg}, \mathrm{mg} / \mathrm{kg}$ & As, $\mathrm{mg} / \mathrm{kg}$ & & & & & \\
\hline & 0.116 & 2.16 & & & & & \\
\hline
\end{tabular}

Two catalysts were investigated. The first (marked as $\mathrm{KX}$ ) was vanadium $\left(\mathrm{V}_{2} \mathrm{O}_{5}\right)$ catalyst from resources of IPET - Fig. 2a. This is a plate type catalyst often used in SCR installations. The second (marked KP) is a prototype platinum catalyst on a ceramic carrier - Fig. $2 b$. 


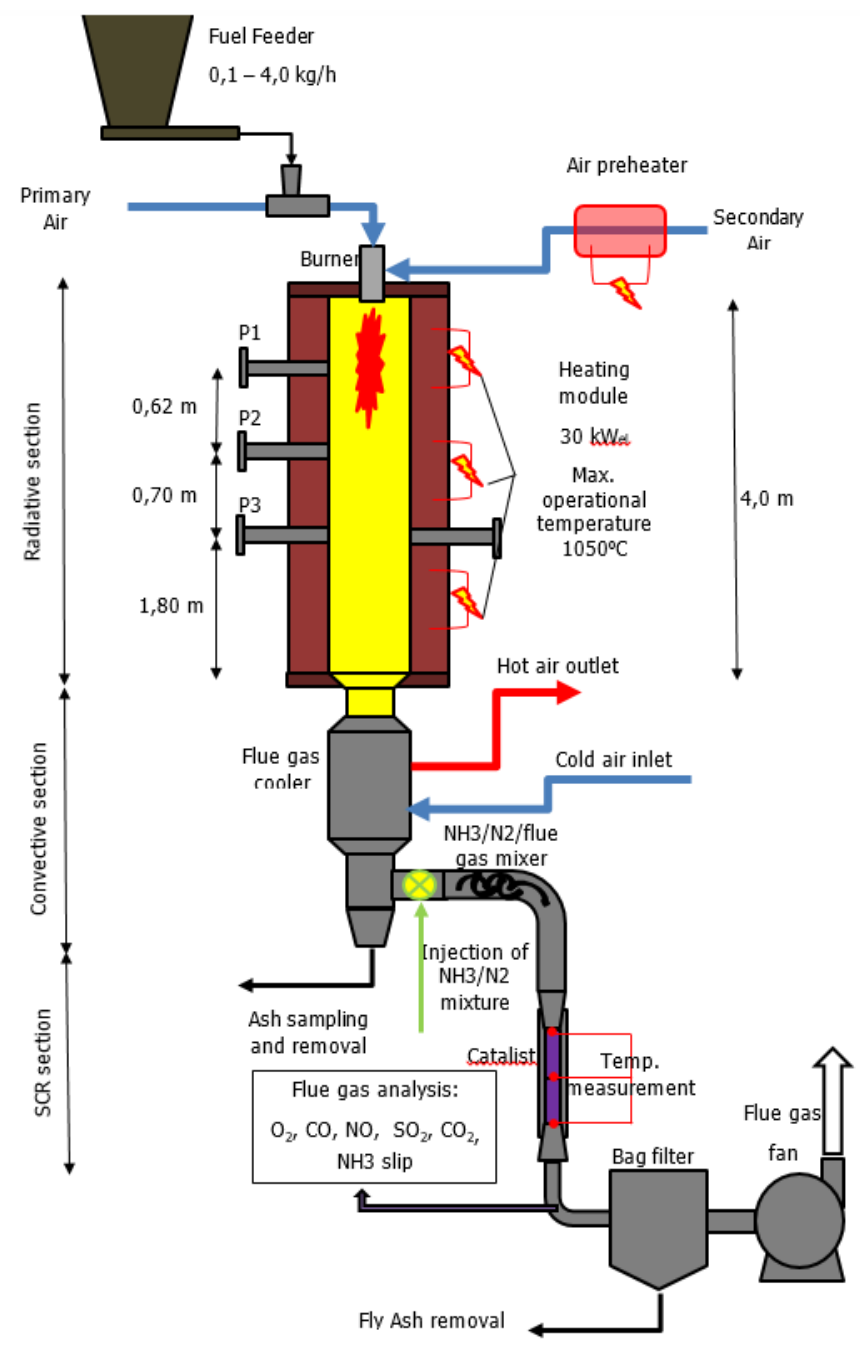

Fig 1. Drop Tube reactor equipped with SCR facility.

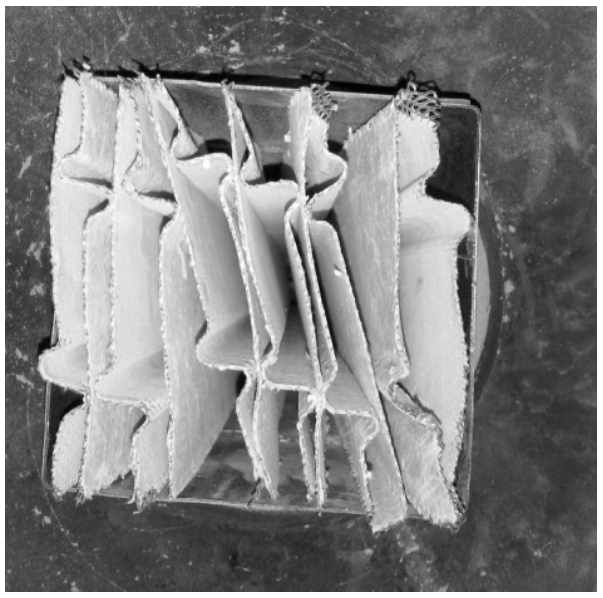

Fig 2a. Catalysts KX installed to lab SCR section 


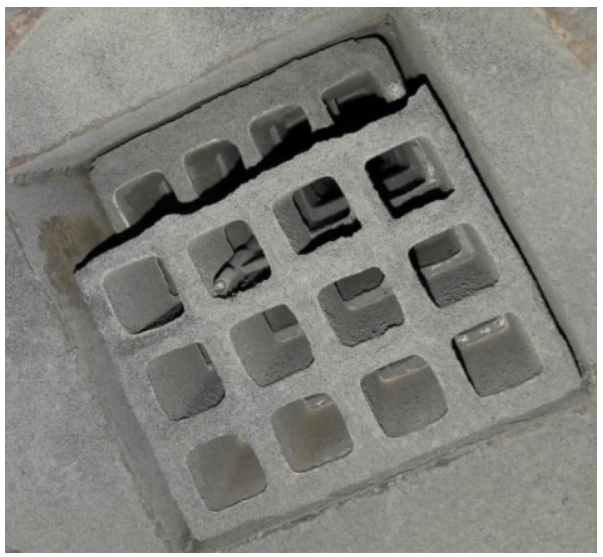

Fig 2b. Catalysts KP installed to lab SCR section

\section{Results and discussion}

\subsection{Catalyst KX}

The results of tests at various temperatures are presented in in Fig. $3-6$. Additionally, the area velocity $\mathrm{AV}\left[\mathrm{m}_{\mathrm{n}} / \mathrm{h}\right]$ value, defined as the quotient of the flue gas stream $\left[\mathrm{m}^{3}{ }_{\mathrm{n}} / \mathrm{h}\right]$ and the contact surface of the catalyst $\left[\mathrm{m}^{2}\right]$, was determined.

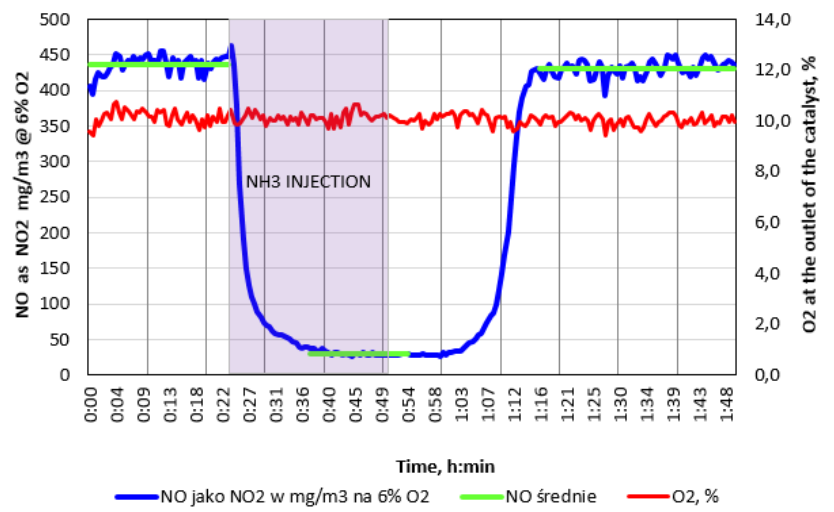

Fig 3. Concentration of $\mathrm{NO}\left(\right.$ as $\left.\mathrm{NO}_{2} @ 6 \% \mathrm{O}_{2}\right)$ and $\mathrm{O}_{2}$ during tests of the $\mathrm{KX}$ catalyst temperature $329^{\circ} \mathrm{C}$. 


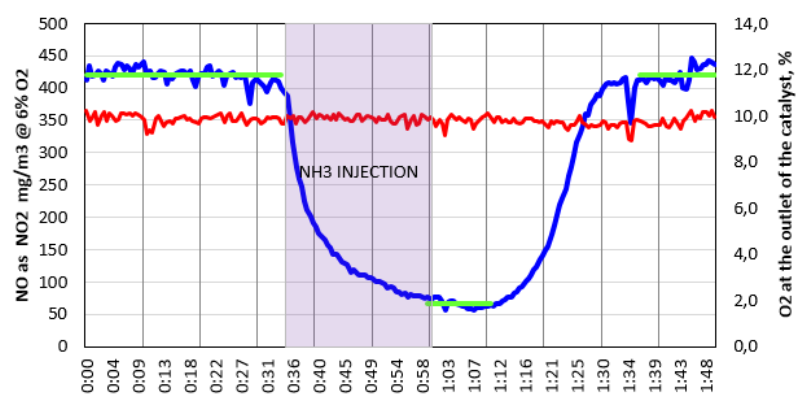

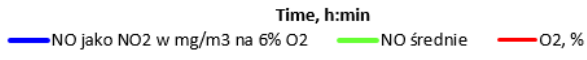

Fig 4. Concentration of $\mathrm{NO}\left(\right.$ as $\left.\mathrm{NO}_{2} @ 6 \% \mathrm{O}_{2}\right)$ and $\mathrm{O}_{2}$ during tests of the $\mathrm{KX}$ catalyst temperature $290^{\circ} \mathrm{C}$.

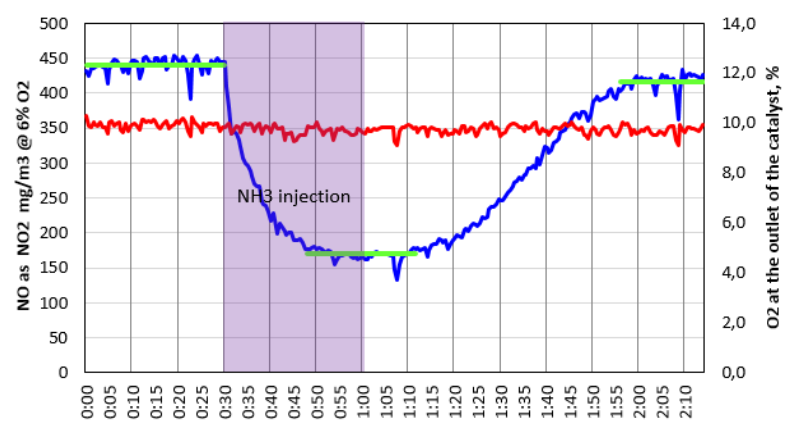

Time, h:min

- $\mathrm{NO}$ jako $\mathrm{NO} 2 \mathrm{w} \mathrm{mg} / \mathrm{m} 3$ na $6 \% \mathrm{O} 2 \longrightarrow$ NO średnie $-\mathrm{O} 2, \%$

Fig 5. Concentration of $\mathrm{NO}\left(\right.$ as $\left.\mathrm{NO}_{2} @ 6 \% \mathrm{O}_{2}\right)$ and $\mathrm{O}_{2}$ during tests of the $\mathrm{KX}$ catalyst temperature $262^{\circ} \mathrm{C}$.

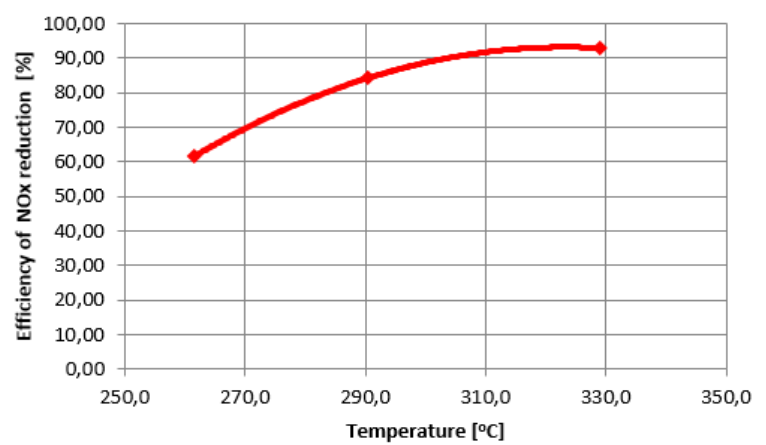

Fig. 6 Efficiency of the KX catalyst versus temperature for $50 \mathrm{mlNH} / \mathrm{min}$.

The AV values were between $6.97-7.22 \mathrm{~m}_{\mathrm{n}} / \mathrm{h}$, what is slightly below the standard for the industrial catalysts according to $[8,10]$. It should be mentioned that with increased AV the efficiency of NOx reduction $\eta_{N O x}$ is lower. The tests for the $\mathrm{NH}_{3}$ stream $300 \mathrm{ml}_{\mathrm{NH} 3} / \mathrm{min}$ and $50 \mathrm{ml}_{\mathrm{NH} 3} / \mathrm{min}$ showed similar results. 


\subsection{Catalyst KP}

The results of tests at various temperatures are presented in Fig 7. The upper (red) curve corresponds to the $\mathrm{NH}_{3}$ stream of $300 \mathrm{ml}_{\mathrm{NH} 3} / \mathrm{min}$ while the lower (blue) curve to the $\mathrm{NH}_{3}$ stream of $50 \mathrm{ml}_{\mathrm{NH} 3} / \mathrm{min}$.

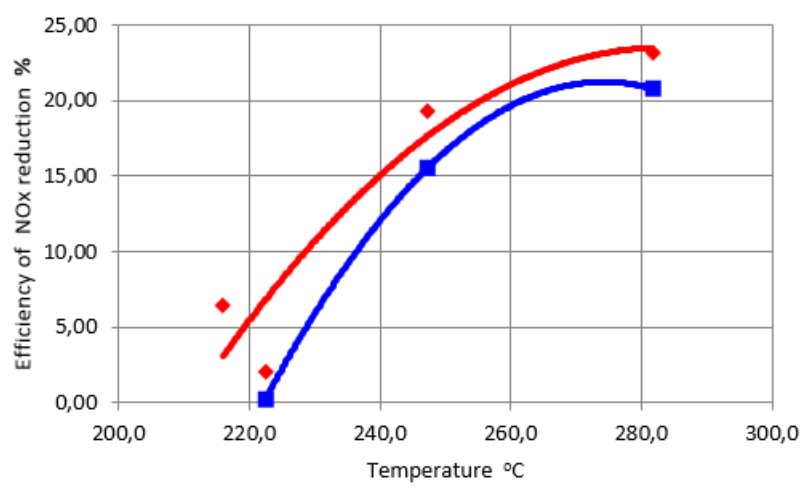

Fig 7. Efficiency of the KP catalyst vs. temperature: red - $300 \mathrm{ml} \mathrm{NH}_{3} / \mathrm{min}$, blue $50 \mathrm{mlNH} / \mathrm{min}$.

The AV calculated for the tests were between $13.06-15.4 \mathrm{~m}_{\mathrm{n}} / \mathrm{h}$. These values are in the standard for the industrial catalysts according to [8, 10]. Compared with $\mathrm{KX}$ with lower $\mathrm{AV}$, such an increase in AV may be responsible for lowering the NOx reduction efficiency $\eta_{N O x}$ by about a dozen percentage points $[8,10]$. Further decrease of $\eta_{N O x}$ was probably caused by the fly ash fouling of the surface of the KP catalyst.

\section{Conclusions}

- The maximum efficiency of NOx reduction obtained for the KX catalyst was $\eta_{N O x} \cong$ $92,87 \%$, for the temperature $329^{\circ} \mathrm{C}$.

- After lowering the temperature to $260{ }^{\circ} \mathrm{C}$ the efficiency was still relatively high and exceeded $60 \%$.

- The KX catalyst shows a strong relationship between efficiency and temperature. This imposes the need to ensure proper flue gas temperatures in the area of its operation. This significantly limits the thickness of the catalytic layer if it is placed on the hot end of the RAH in boilers.

- The results of measurements of the prototype ceramic KP catalyst show its low efficiency, not exceeding $\eta_{N O x} \cong 23 \%$. This is probably due to its sensitivity to fly ash fouling. Such a catalyst was more effective in a test conducted for natural gas combustion gases [9].

Given the above, further research should focus on the study of commercial catalysts that provide high levels of $\eta_{N O x}$. However, it is necessary to test the suitability of such catalysts for use in RAH. They must then meet two basic conditions: 
- adequate mechanical strength in operating conditions as a heating element for the mobile RAH rotor,

- the ability to transfer the appropriate heat flux in the preheater.

Such tests can be carried out only on the model ROPP or on the real object in industry.

\section{Acknowledgements}

Investigations presented in this work were financed within the project „Hybrydowa technologia odazotowania spalin w kotłach energetycznych" (Hybrid technology of NOx reduction in the flue gas from utility boilers) within the framework of the Regional Operational Programme for Opolskie Voivodship 2014-2020 and the framework of the BKM/561/RIE5/2017 project of the Silesian University of Technology.

\section{References}

1. Directive 2010/75/EU of the European Parliament and of the Council of 24 November 2010 on industrial emissions (integrated pollution prevention and control). L 334/17.

2. Commission Implementing Decision (EU) 2017/1442 of 31 July 2017 establishing best available techniques (BAT) conclusions, under Directive 2010/75/EU of the European Parliament and of the Council, for large combustion plants (notified under document C(2017) 5225).

3. M. Kułażyński: Selective Catalytic Reduction NO by Ammonia Over Ceramic and Active Carbon Based Catalysts - Heat Analysis and Thermodynamic Effects. Intech Europe, 2011

4. J. L. Sorrels, D. D. Randall, K. S. Schaffner, C. Richardson Fry: Selective Catalytic Reduction (SCR) Cost Manual Chapter 7th Edition (2016). EPA-HQOAR-2015-0341-0032.

5. C. Xingxing, T. Bi. Xiaotao: A review of recent advances in selective catalytic NOx reduction reactor technologies. Particuology 16 (2014) 1-18.

6. S. Hirschberg: Static mixers for flue gas treatment applications. Sulzer Chemtech, (2011).

7. K. Rajendran: Ammonia Injection and Mixing Systems 101. 2018 NOxCombustion-CCR Round Table February 19, (2018) St Louis, MO.

8. M. Hilber, H. Thorwarth: Lab-scale assessment of different parameters influencing the operational behaviour of SCR-DENOX-catalysts. VGB PowerTech 10/2012.

9. R. Wejkowski, W. Wojnar: Selective Catalytic Reduction in a Rotary Air Heater (SCR - RAH). Energy 145 (2018) 367-373.

10. Hitachi Zosen Engineering U.S.A. LTD SCR Catalyst Performance on U.S. Coal Fired Boilers. 2002 Conference on Selective Catalytic Reduction and NonCatalytic Reduction for NOx Control Pittsburgh, Pennsylvania, USA May 16, (2002). 